\title{
Gompertz and Logistic Models to the Productive Traits of Sunn Hemp
}

\author{
Cláudia Marques de Bem ${ }^{1}$, Alberto Cargnelutti Filho², Gabriela Görgen Chaves ${ }^{1}$, Jéssica Andiara Kleinpaul ${ }^{1}$, \\ Rafael Vieira Pezzini ${ }^{1} \&$ André Lavezo $^{1}$ \\ ${ }^{1}$ Postgraduate Program in Agronomy, Federal University of Santa Maria, Santa Maria, Brazil \\ ${ }^{2}$ Department of Crop Science, Federal University of Santa Maria, Santa Maria, Brazil \\ Correspondence: Alberto Cargnelutti Filho, Avenida Roraima, no 1000, Bairro Camobi, CEP 97105-900, Santa \\ Maria, RS, Brazil. Tel: 55-55-3220-8899. E-mail: alberto.cargnelutti.filho@gmail.com
}

Received: September 26, 2017

Accepted: November 6, 2017 Online Published: December 15, 2017

doi:10.5539/jas.v10n1p225

URL: https://doi.org/10.5539/jas.v10n1p225

\begin{abstract}
Studies on growth models for productive character of sunn hemp are important to know the behavior of the culture. Therefore, the objective of this research was to adjust non-linear models, Gompertz and Logistic, in the description of productive traits of sunn hemp in two sowing periods. Two uniformity trials were performed. The evaluations began on October the $29^{\text {th }} 2014$ and December the $16^{\text {th }} 2014$, totaling 94 and 76 evaluation days for periods 1 and 2, respectively. After the emergence of the seeds of sunn hemp, for first period from 7 days after sowing, and from 2 to 13 days after sowing, on each day, they were collected randomly four plants. The traits: fresh matter leaf, stem, root, shoot, and total, and dry matter leaf, stem, root, shoot, and total. For both models the confidence interval was calculated of parameters $a, b$ and $c$. The adjustment quality of the Gompertz and Logistic models was verified by the determination coefficient, the Akaike information criteria, residual standard deviation, mean absolute deviation, mean absolute percentage error and mean prediction error. The Gompertz model when compared between the sowing periods through the confidence interval of the parameters, for the productive traits, differs. The same result was found for the Logistic model. The growth models of Gompertz and Logistic presented good adjustment quality.
\end{abstract}

Keywords: Crotalaria juncea, dry matter, fresh matter, nonlinear models

\section{Introduction}

The sunn hemp (Crotalaria juncea L.) is a fast-growing species, used as rotating green manure with various crops. According to Wutke, Calegari, and Wildner (2014), sunn hemp has potential for cultivation in both the southeast and Center-West regions as well as in the south region of Brazil as "soil improver" and "recuperate", besides being tolerant to soils of medium fertility. This species stands out among legumes, producing a high amount of dry matter mass per area (Sousa, 2011).

One way to characterize the growth of gives culture is by modeling (Streck, Bosco, Lucas, \& Lago, 2008). According to Gomes, Robaina, Peiter, Soares, and Parizi (2014), the crops growth simulation models are important tools to determine the best sowing date, to forecast crops in different scenarios. Currently, several researchers are studying the relationship between two variables, the behavior of a dependent variable as a function of another independent variable(s). The relation can be described by means of mathematical functions, these being denominated regression models.

The analysis of growth curves, involving the adjustment of non-linear regression models, is used to estimate the causes of growth and to infer about the contributions of the various processes present in plant development. According to Fernandes, Pereira, Muniz, and Savian (2014), the study of growth curves, through non-linear models, synthesizes information from a set of date. Among the several models that are used for this purpose, the Gompertz and Logistic models stand out, which contribute or facilitate the interpretation of the processes involved in plant growth, sincerity parameters allow efficient practical interpretations.

The adjustment of non-linear models has been studied in several areas of in the comparison of different non-linear models in banana (Maia, Siqueira, Silva, Peternelli, \& Salomão, 2009), Logistic model in describing the growth of fruit dwarf coconut (Prado, Savian, \& Muniz, 2013); in the study of models for the estimation of productivity for the soybean crop (Gomes et al., 2014); do not adjust Logistic model of the maize height date (Mangueira, Savian, Muniz, Sermarini, \& Crosariol Neto, 2016) and the study of the Gompertz and Logistic 
models in the description of cocoa fruit growth (Muniz, Nascimento, \& Fernandes, 2017). Therefore, studies on growth models for productive character of sunn hemp are important to know the behavior of the culture, but no work has been found in the literature. It is assumed that these models can adequately describe the productive characteristics of green and dry matter mass of leaf, stem, root, shoot and total of sunn hemp.

The objective of this research was to adjust the non-linear models, Gompertz and Logistic, in the description of the productive character of sunn hemp (Crotalaria juncea L.) at two sowing date.

\section{Material and Methods}

Two uniformity trials (experiments without treatments) were conducted with sunn hemp (Crotalaria juncea $\mathrm{L}$.) during the 2014/2015 harvest, in an experimental area of the Department of Plant Science at the Federal University of Santa Maria, Rio Grande do Sul State. The sunn hemp seeds were sown on two periods, the first sowing period on October 22, 2014 and the second period on December 3, 2014. On both periods, was performed in rows $0.5 \mathrm{~m}$ apart with a density of 20 plants per row meter in a usable area of $52 \mathrm{~m} \times 50 \mathrm{~m}\left(2.600 \mathrm{~m}^{2}\right)$.

After the emergence of the seeds of sunn hemp, for first period from 7 days after sowing (October 29, 2014), and from 2 to 13 days after sowing (December 16, 2014), on each day, they were collected randomly four plants, totaled 94 and 76 evaluation days, respectively. The traits were evaluated fresh matter leaf (FML), fresh matter stem(FMS) fresh matter root (FMR), fresh matter shoot $($ FMSH $=$ FML + FMS $)$, the total fresh matter $($ FMT = FML + FMS + FMR), dry matter leaf (DML), dry matter stem (DMS), dry matter root (DMR), dry matter shoot $(\mathrm{DMSH}=\mathrm{DML}+\mathrm{DMS})$, and total dry matter $(\mathrm{DMT}=\mathrm{DML}+\mathrm{DMS}+\mathrm{DMR})$. The leaf fresh matter leaf, stem and root in $\mathrm{g}$ were obtained by digital weighing, and the material was oven dried at $60{ }^{\circ} \mathrm{C}$ with forced ventilation until constant weight was reached to obtain the dry matter leaf, stem and root.

For these productive traits, the Gompertz and Logistic models were fitted as a function of days after sowing (DAS).

The Gompertz model was given by the equation:

$$
y i=a \cdot e^{\left(-e^{(b-c \cdot x i)}\right)}
$$

and, the Logistic model was given by the equation:

$$
y i=\frac{a}{1+e^{(-b-c \cdot x i)}}
$$

where, $y i$ is the it observation of the dependent variable, with $i=1,2, \ldots, \mathrm{n}$ and $\mathrm{n}$ is number the observation; $x i$ is the ith observation of the independent variable; $a$ is the asymptotic value; $b$ is a location parameter without direct practical interpretation but with importance for maintaining the sigmoidal shape of the model; $c$ is associated with growth and indicates the rate of maturity or precociousness. The higher the value of $c$, the less time is required for the plant to reach the asymptotic value $(a)$.

The Gompertz model, the inflection point (IP) was calculated by:

$$
x i=\frac{b}{c}
$$

and,

maximum acceleration point (map):

$$
y i=\frac{a}{e}
$$

$$
x i=\left(\frac{b-\ln (2.6180)}{c}\right)
$$

and,

$$
y i=a \cdot e^{(-2.6180)}
$$

maximum deceleration point (mdp):

$$
x i=\left(\frac{b-\ln (0.3819)}{c}\right)
$$

and,

$$
y i=a \cdot e^{(-0.3819)}
$$

asymptotic deceleration point (adp):

$$
x i=\left(\frac{b-\ln (0.1657)}{c}\right)
$$


and,

$$
y i=a \cdot e^{(-0.1657)}
$$

where, $a, b$, and $c$ are model parameters, and $e$ is the base of the neperiano logarithm (Mischan \& Pinho, 2014).

Also, the Logistic model, the inflection point (IP) was calculated by:

$$
x i=\frac{-b}{c}
$$

and,

$$
y i=\frac{a}{2}
$$

maximum acceleration point (map):

$$
x i=\left(\frac{-b}{c}\right)-\left(\left(\frac{1}{c}\right) \times 1.3170\right)
$$

and,

maximum deceleration point (mdp):

$$
y i=\frac{a}{4.7321}
$$

and,

$$
x i=\left(\frac{-b}{c}\right)+\left(\left(\frac{1}{c}\right) \times 1.3170\right)
$$

and, asymptotic deceleration point (adp):

$$
y i=\frac{a}{1.2679}
$$

and,

$$
x i=\left(\frac{-b}{c}\right)+\left(\left(\frac{1}{c}\right) \times 2.2924\right)
$$

$$
y i=\frac{a}{1.1010}
$$

where, $a, b$, and $c$ are model parameters, and $e$ is the base of the neperiano logarithm (Mischan \& Pinho, 2014).

Subsequently, the comparison between the growth models adjusted for the traits evaluated, adopted the criterion of overlapping the confidence intervals of the parameters estimated for each model. For this, a growth curve was adjusted for each traits, obtaining the limits of the confidence intervals at $100 \times(1-\alpha)$ for the parameters. The comparison will be made by checking whether or not the respective intervals coincide. For example, to compare the epochs for the same traits, when at least one parameter estimate of a traits for a given period contained in the confidence interval of the same traits parameter of another period, they do not differ. However, if none of the estimates are contained in the confidence interval of the other, the parameter estimates differ between them. Statistical software R (R Development Core Team, 2017) was used for this analysis.

The following parameters were utilized to evaluate the goodness of fit of the Gompertz and Logistic models: coefficient of determination:

$$
R^{2}=S Q R / S Q T
$$

where, $S Q R$ is the sum of residue square, $S Q T$ is the sum of total square, the best model had the highest $R^{2}$ value; Akaike information criterion:

$$
A I C=\ln \left(\sigma^{2}\right)+2(p+1) / n
$$

where, $\ln \left(\sigma^{2}\right)$ is the logarithm of the variance model, $p$ is parameter of model, and $n$ is number of parameters model, the best model had the lowest value; standard deviation of the residuals:

$$
S D R=\sqrt{M S E}
$$

where, $M S E$ is the mean square error, the lower the $Q M R$ value, the better the fit of the model; mean absolute deviation:

$$
M A D=\frac{\sum_{i=1}^{n}|y i-\hat{y}| \mid}{n}
$$

the lower the value, the better the fit of the model; mean absolute percentage error:

$$
\text { MAPE }=\frac{\sum_{i=1}^{n}\left|\frac{|y-\widehat{y}|}{y i}\right|}{n} \times 100
$$


the best fitting model had the lowest value; and mean prediction error:

$$
M P E=\frac{1}{n} \sum_{i=1}^{n} E P i
$$

measures the adherence of the estimated data to the obtained data (Maia et al., 2009). The calculations were performed with the help of Microsoft Office Excel ${ }^{\circledR}$ application and software statistic R (R Development Core Team, 2017).

\section{Results and Discussion}

After the Gompertz and Logistic models were established, their suitability was investigated based on the residues. But for the traits FML, FMR, and DMR at the first period, and the traits FML and DML in second period, were transformed through Box-Cox transformation to which these assumptions were met.

By means of the Shapiro-Wilk test, the assumption of residual normality was met in both models for both sowing periods, since this test had a p-value greater than 0.05 for all traits studied. For the test Breusch- Pagan, also based on p-value, it can be inferred that the residual variances were homogeneous in all the traits of the two sowing periods $(\mathrm{p}>0.05)$. Through the Durbin-Watson test, with significance level of $5 \%$, it was found that the residues attended the inde pendence assumption $(\mathrm{p}<0.05)$ for all traits in two sowing periods (Table 1 ).

Table 1. Value-p of the Shapiro-Wilk (SW), Breusch-Pagan (BP) and Durbin-Watson (DW) tests applied on Gompertz and Logistic model residues for the productive traits of sunn hemp in two sowing periods

\begin{tabular}{|c|c|c|c|c|c|c|c|}
\hline \multirow[t]{2}{*}{ Traits } & \multirow[t]{2}{*}{ Model } & \multicolumn{3}{|c|}{$\begin{array}{l}\text { First sowing period } \\
\text { (October 22, 2014) }\end{array}$} & \multicolumn{3}{|c|}{$\begin{array}{l}\text { Second sowing period } \\
\text { (December } 3,2014 \text { ) }\end{array}$} \\
\hline & & SW & $\mathrm{BP}$ & DW & SW & $\mathrm{BP}$ & DW \\
\hline \multirow[t]{2}{*}{ FML } & Gompertz & 0.0500 & 0.1007 & 0.0576 & 0.0817 & 0.0500 & 0.0817 \\
\hline & Logístico & 0.0769 & 0.1510 & 0.0542 & 0.0527 & 0.0501 & 0.0616 \\
\hline \multirow[t]{2}{*}{ FMS } & Gompertz & 0.0576 & 0.0658 & 0.9793 & 0.2983 & 0.2706 & 0.1124 \\
\hline & Logístico & 0.1684 & 0.0500 & 0.9463 & 0.0648 & 0.4048 & 0.1357 \\
\hline \multirow[t]{2}{*}{ FMR } & Gompertz & 0.0963 & 0.3960 & 0.5389 & 0.0619 & 0.0654 & 0.7159 \\
\hline & Logístico & 0.1065 & 0.5155 & 0.5005 & 0.1134 & 0.0760 & 0.7496 \\
\hline \multirow[t]{2}{*}{ FMSH } & Gompertz & 0.0589 & 0.1651 & 0.7700 & 0.1745 & 0.0900 & 0.1345 \\
\hline & Logístico & 0.1807 & 0.1393 & 0.5958 & 0.0508 & 0.1503 & 0.1236 \\
\hline \multirow[t]{2}{*}{ FMT } & Gompertz & 0.0501 & 0.1088 & 0.8198 & 0.2317 & 0.1213 & 0.1969 \\
\hline & Logístico & 0.0745 & 0.0966 & 0.6693 & 0.0548 & 0.1901 & 0.1879 \\
\hline \multirow[t]{2}{*}{$\mathrm{DML}$} & Gompertz & 0.0879 & 0.1738 & 0.3103 & 0.2449 & 0.0500 & 0.2583 \\
\hline & Logístico & 0.1292 & 0.1726 & 0.2321 & 0.2290 & 0.0502 & 0.3173 \\
\hline \multirow[t]{2}{*}{ DMS } & Gompertz & 0.8002 & 0.8067 & 0.9881 & 0.4266 & 0.3728 & 0.9039 \\
\hline & Logístico & 0.8131 & 0.0500 & 0.9874 & 0.3348 & 0.3589 & 0.9124 \\
\hline \multirow[t]{2}{*}{$\mathrm{DMR}$} & Gompertz & 0.2777 & 0.7099 & 0.1628 & 0.1790 & 0.1569 & 0.6076 \\
\hline & Logístico & 0.1042 & 0.4578 & 0.5698 & 0.1602 & 0.1893 & 0.6385 \\
\hline \multirow[t]{2}{*}{ DMSH } & Gompertz & 0.4391 & 0.2132 & 0.9284 & 0.3873 & 0.2884 & 0.8790 \\
\hline & Logístico & 0.0694 & 0.5642 & 0.9184 & 0.0773 & 0.2421 & 0.8545 \\
\hline \multirow[t]{2}{*}{ DMT } & Gompertz & 0.2322 & 0.3253 & 0.7270 & 0.4455 & 0.2395 & 0.7089 \\
\hline & Logístico & 0.1481 & 0.3070 & 0.9298 & 0.0544 & 0.1288 & 0.6085 \\
\hline
\end{tabular}

Note. ${ }^{*} \mathrm{FML}=$ fresh matter leaf; FMS $=$ fresh matter stem; FMR $=$ fresh matter root; FMSH $=$ fresh matter shoot and $\mathrm{FMT}=$ total fresh matter; DML $=$ dry matter leaf; DMS = dry matter stem; DMR = dry matter root; DMSH $=$ dry matter shoot and DMT $=$ total dry matter.

Therefore, the Gompertz and Logistic models are suitable for adjusting the productive traits of sunn hemp. In study on nonlinear models for description of cacao fruit growth with assumption violations, Muniz et al. (2017), verified the importance of performing the residual analysis.

For the comparison of the model parameters estimates between sowing periods, the criterion of overlapping the confidence intervals of the parameters estimates for each model was used. It is observed that for the Gompertz model to FML, the estimate of the parameter $a$ in first period was 49.32. This estimate was higher than the LI 
and less than the LS $95 \%$ of the estimate parameter $a$ in second period, that is, is with in $95 \%$ of the estimate of the parameter $a$ at the second period. The estimate of the parameter $a$ at the second period was 49.36 . This estimate was higher than the LI and less than the LS $95 \%$ of the parameter estimates $a$ in the first period, or is with in $95 \%$ of the parameter estimates $a$ in the first period. Therefore, the estimates of the parameter $a$ of the periods do not differ to a 5\% probability (non-significant effect). However, for the parameters $b$ and $c$ it is observed that there was a significant difference (Table 2).

Table 2. Estimates of the parameters, and respective standard errors (EP) and lower (LI) and upper (LS) limits of the $95 \%$ confidence interval, in the fit of the productive traits of fresch matter mass of sunn hemp in two sowing periods

\begin{tabular}{|c|c|c|c|c|c|c|c|c|c|}
\hline \multirow[t]{2}{*}{ Traits } & \multirow[t]{2}{*}{ Parameters } & \multicolumn{4}{|c|}{$\begin{array}{l}\text { First sowing period } \\
\text { (October 22, 2014) }\end{array}$} & \multicolumn{4}{|c|}{$\begin{array}{c}\text { Second sowing period } \\
\text { (December } 3,2014)\end{array}$} \\
\hline & & Estimation & EP & LI & LS & Estimation & EP & LI & LS \\
\hline \multicolumn{10}{|c|}{ Model of Gompertz } \\
\hline \multirow[t]{3}{*}{ FML } & $a(\mathrm{~ns})$ & 49.32 & 2.5513 & 44.16 & 57.66 & 49.36 & 12.514 & 34.44 & 148.63 \\
\hline & $b(*)$ & 3.38 & 0.5402 & 2.3742 & 5.2469 & 2.18 & 0.3814 & 1.6803 & 3.3017 \\
\hline & $c(*)$ & 0.0712 & 0.0118 & 0.0472 & 0.1128 & 0.0373 & 0.0111 & 0.0166 & 0.0660 \\
\hline \multirow[t]{3}{*}{ FMS } & $a(*)$ & 128.89 & 11.70 & 110.79 & 162.97 & 201.92 & 190.51 & 190.22 & 231.12 \\
\hline & $b$ (ns) & 2.90 & 0.4042 & 2.2590 & 3.7939 & 2.37 & 0.4001 & 2.1213 & 3.8777 \\
\hline & $c(*)$ & 0.0498 & 0.0085 & 0.0351 & 0.0682 & 0.0309 & 0.0098 & 0.0270 & 0.0401 \\
\hline \multirow[t]{3}{*}{ FMR } & $a(*)$ & 31.11 & 2.8585 & 26.88 & 39.13 & 41.32 & 2.4500 & 36.97 & 47.652 \\
\hline & $b(*)$ & 3.24 & 0.5120 & 2.4246 & 4.3775 & 2.02 & 0.3550 & 1.8701 & 2.4532 \\
\hline & $c(*)$ & 0.0550 & 0.0102 & 0.0377 & 0.0768 & 0.0226 & 0.0088 & 0.0189 & 0.0304 \\
\hline \multirow[t]{3}{*}{ FMSH } & $a(*)$ & 179.18 & 14.000 & 156.06 & 220.70 & 274.09 & 18.700 & 245.67 & 296.12 \\
\hline & $b(*)$ & 2.86 & 0.3942 & 2.2119 & 3.7776 & 2.21 & 0.3221 & 1.9804 & 2.4301 \\
\hline & $c(*)$ & 0.0521 & 0.0085 & 0.0367 & 0.0718 & 0.0292 & 0.0093 & 0.0268 & 0.0312 \\
\hline \multirow[t]{3}{*}{ FMT } & $a(*)$ & 211.43 & 16.820 & 184.13 & 260.36 & 315.41 & 21.901 & 298.76 & 330.32 \\
\hline & $b\left(^{*}\right)$ & 2.87 & 0.3940 & 2.2348 & 3.7760 & 2.18 & 0.3150 & 1.9700 & 2.2908 \\
\hline & $c(*)$ & 0.0517 & 0.0084 & 0.0367 & 0.0708 & 0.0283 & 0.0096 & 0.0275 & 0.0309 \\
\hline \multicolumn{10}{|c|}{ Model Logistic } \\
\hline \multirow[t]{3}{*}{ FML } & $a(*)$ & 46.56 & 1.7895 & 42.227 & 52.352 & 39.16 & 5.2881 & 37.15 & 45.677 \\
\hline & $b(\mathrm{~ns})$ & -5.95 & 0.8184 & -9.855 & -4.412 & -4.58 & 0.6098 & -8.500 & -3.512 \\
\hline & $c(*)$ & 0.1146 & 0.0167 & 0.0796 & 0.2009 & 0.0752 & 0.0143 & 0.0123 & 0.1091 \\
\hline \multirow[t]{3}{*}{ FMS } & $a(*)$ & 115.80 & 6.5474 & 104.19 & 132.86 & 201.92 & 190.49 & 190.00 & 230.10 \\
\hline & $b(\mathrm{~ns})$ & -5.53 & 0.5888 & -6.777 & -4.623 & -5.28 & 0.3609 & -6.600 & -4.550 \\
\hline & $c(\mathrm{~ns})$ & 0.0871 & 0.0109 & 0.0687 & 0.1107 & 0.0613 & 0.0108 & 0.0105 & 0.0915 \\
\hline \multirow[t]{3}{*}{ FMR } & $a(*)$ & 28.05 & 1.5719 & 25.38 & 31.88 & 39.22 & 2.4428 & 36.90 & 47.81 \\
\hline & $b(*)$ & -6.22 & 0.7633 & -7.887 & -5.025 & -4.87 & 0.2890 & -5.3501 & -3.780 \\
\hline & $c\left(^{*}\right)$ & 0.0976 & 0.0136 & 0.0753 & 0.1269 & 0.0505 & 0.0100 & 0.0350 & 0.0701 \\
\hline \multirow[t]{3}{*}{ FMSH } & $a(*)$ & 164.36 & 8.4972 & 148.42 & 187.33 & 238.68 & 19.914 & 210.12 & 270.31 \\
\hline & $b(\mathrm{~ns})$ & -5.28 & 0.5650 & -6.521 & -4.390 & -4.87 & 0.2476 & -5.3200 & -3.550 \\
\hline & $c(\mathrm{~ns})$ & 0.0871 & 0.0108 & 0.0683 & 0.1122 & 0.0599 & 0.0095 & 0.0101 & 0.0910 \\
\hline \multirow[t]{3}{*}{ FMT } & $a(*)$ & 193.13 & 10.016 & 174.71 & 219.52 & 281.63 & 125.87 & 260.12 & 300.01 \\
\hline & $b$ (ns) & -5.36 & 0.5679 & -6.582 & -4.466 & -4.85 & 0.3149 & -6.400 & -4.531 \\
\hline & $c\left(^{*}\right)$ & 0.0875 & 0.0108 & 0.0692 & 0.1112 & 0.0582 & 0.0112 & 0.0368 & 0.0710 \\
\hline
\end{tabular}

Note ${ }^{* *} \mathrm{FML}=$ fresh matter leaf; FMS $=$ fresh matter stem; FMR $=$ fresh matter root; FMSH $=$ fresh matter shoot and $\mathrm{FMT}=$ total fresh matter.

To estimate the parameter $a$ significant effect for the traits FML, FMS, FMSH and FMT; to $b$ significant effect parameter to the traits FMS, FMSH and FMT; and $c$ significant effect parameter to the traits FML, FMS, FMR, 
FMSH and FMT (Table 2). So for the Gompertz model, the parameter estimates $a, b$ and $c$ differ a $5 \%$ probability between the sowing periods.

Reading the Logistic model, it is observed that for the parameter $a$ significant effect on the traits FML, FMS, FMR, FMSH and FMT; for the parameter $b$, a significant effect only for the character MVR; and the $c$ significant effect parameter to the traits FML, FMR and FMT. So for the Logistic model, the parameter estimates $a, b$ and $c$ differ a 5\% probability between sowing periods (Table 2). These results are important as it is observed that sowing periods have influence on the production of fresh matter mass in sunn hemp, and for productive purposes second period provided higher values of fresh matter mass. In study on to fit Gompertz and Logistic nonlinear to descriptions of morphological traits of sunn hemp, Bem, Cargnelutti Filho, Facco, Schabarum, Silveira, Simões, and Uliana (2017), also used for the comparison of the model parameters estimates between sowing periods, the criterion of overlapping the confidence intervals, highlighting the importance of this methodology.

In relation to the mass of dry matter, it is observed for the Gompertz model for DML, DMS, DMSH and DMT, significant effect on the parameter $a$, to the parameter $\mathrm{b}$, a significant effect only for the character DML, and parameter c, a significant effect on the traits DML and DMSH (Table 3). Therefore, it is concluded that the estimates of the parameters $a$ and $b$ of periods differ at $5 \%$ probability. For Logistic model, it is observed that for the parameter, there was a significant effect for all productive traits for the parameter $b$ and $c$, a significant effect on the character DMR (Table 3). 
Table 3. Estimates of the parameters, and respective standard errors (EP) and lower (LI) and upper (LS) limits of the $95 \%$ confidence interval, in the fit of the productive traits of dry matter mass of sunn hemp in two sowing periods

\begin{tabular}{|c|c|c|c|c|c|c|c|c|c|}
\hline \multirow[t]{2}{*}{ Traits } & \multirow[t]{2}{*}{ Parameters } & \multicolumn{4}{|c|}{$\begin{array}{l}\text { First sowing period } \\
\text { (October 22, 2014) }\end{array}$} & \multicolumn{4}{|c|}{$\begin{array}{l}\text { Second sowing period } \\
\text { (December } 3,2014 \text { ) }\end{array}$} \\
\hline & & Estimation & $\mathrm{EP}$ & LI & LS & Estimation & EP & LI & LS \\
\hline \multicolumn{10}{|c|}{ Model of Gompertz } \\
\hline \multirow[t]{3}{*}{ DML } & $a(\mathrm{~ns})$ & 11.56 & 0.9300 & 10.09 & 14.24 & 26.74 & 1.6300 & 23.15 & 31.00 \\
\hline & $b(*)$ & 2.89 & 0.4400 & 2.1809 & 3.8914 & 2.09 & 0.6640 & 1.9402 & 2.4304 \\
\hline & $c(*)$ & 0.0536 & 0.0094 & 0.0371 & 0.0748 & 0.0238 & 0.0110 & 0.0101 & 0.0302 \\
\hline \multirow[t]{3}{*}{ DMS } & $a(*)$ & 33.19 & 3.4212 & 28.28 & 42.96 & 95.64 & 7.8100 & 90.05 & 100.30 \\
\hline & $b(\mathrm{~ns})$ & 3.51 & 0.5236 & 2.6575 & 4.7132 & 3.58 & 0.5500 & 2.7501 & 4.8004 \\
\hline & $c(*)$ & 0.0542 & 0.0097 & 0.0375 & 0.0754 & 0.0415 & 0.0088 & 0.0355 & 0.0690 \\
\hline \multirow[t]{3}{*}{ DMR } & $a(*)$ & 9.76 & 1.1280 & 8.24 & 13.09 & 12.99 & 0.7445 & 10.40 & 17.03 \\
\hline & $b(*)$ & 3.67 & 0.6672 & 2.1115 & 5.2218 & 2.27 & 0.6680 & 2.1680 & 5.2311 \\
\hline & $c(*)$ & 0.0575 & 0.0123 & 0.0369 & 0.0841 & 0.0252 & 0.0011 & 0.0192 & 0.0303 \\
\hline \multirow[t]{3}{*}{ DMSH } & $a(*)$ & 46.17 & 4.7840 & 39.33 & 59.63 & 115.28 & 9.7093 & 110.00 & 125.90 \\
\hline & $b(*)$ & 3.11 & 0.4415 & 2.4055 & 4.0816 & 3.03 & 0.4402 & 2.4321 & 4.1012 \\
\hline & $c(*)$ & 0.0497 & 0.0087 & 0.0347 & 0.0680 & 0.0354 & 0.0900 & 0.0270 & 0.0412 \\
\hline \multirow[t]{3}{*}{$\mathrm{DMT}$} & $a(*)$ & 56.07 & 5.7535 & 47.88 & 72.09 & 127.11 & 10.050 & 112.12 & 134.06 \\
\hline & $b(*)$ & 3.18 & 0.4557 & 2.4570 & 4.1894 & 2.98 & 0.4776 & 2.5031 & 4.2345 \\
\hline & $c(*)$ & 0.0507 & 0.0089 & 0.0348 & 0.0693 & 0.0342 & 0.0909 & 0.0268 & 0.0421 \\
\hline \multicolumn{10}{|c|}{ Model Logistic } \\
\hline \multirow[t]{3}{*}{ DML } & $a(*)$ & 10.66 & 0.5727 & 9.65 & 12.12 & 26.74 & 1.6213 & 23.12 & 30.14 \\
\hline & $b(\mathrm{~ns})$ & -5.34 & 0.6306 & -6.690 & -4.351 & -5.13 & 0.6210 & -6.300 & -4.300 \\
\hline & $c(*)$ & 0.0895 & 0.0123 & 0.0691 & 0.1163 & 0.0536 & 0.0120 & 0.0750 & 0.1100 \\
\hline \multirow[t]{3}{*}{ DMS } & $a(*)$ & 28.86 & 1.6542 & 26.07 & 32.96 & 95.64 & 7.8120 & 90.12 & 100.79 \\
\hline & $b(\mathrm{~ns})$ & -7.00 & 0.7893 & -8.789 & -5.731 & -8.74 & 0.0905 & -9.001 & -7.600 \\
\hline & $c(\mathrm{~ns})$ & 0.1021 & 0.0131 & 0.0800 & 0.1314 & 0.0966 & 0.0113 & 0.0800 & 0.1210 \\
\hline \multirow[t]{3}{*}{ DMR } & $a(*)$ & 8.64 & 0.5682 & 7.74 & 10.01 & 12.99 & 0.7444 & 10.23 & 16.00 \\
\hline & $b(*)$ & -7.26 & 1.0076 & -9.515 & -5.675 & -5.67 & 0.6300 & -6.3800 & -4.200 \\
\hline & $c(*)$ & 0.1066 & 0.0166 & 0.0798 & 0.1428 & 0.0589 & 0.0810 & 0.0510 & 0.0700 \\
\hline \multirow[t]{3}{*}{ DMSH } & $a(*)$ & 40.15 & 2.3365 & 36.36 & 45.85 & 115.28 & 9.7090 & 100.01 & 123.00 \\
\hline & $b(\mathrm{~ns})$ & -6.23 & 0.6683 & -7.671 & -5.165 & -7.29 & 0.7788 & -8.600 & -5.500 \\
\hline & $c(\mathrm{~ns})$ & 0.0932 & 0.0117 & 0.0737 & 0.1179 & 0.0801 & 0.0105 & 0.0721 & 0.0914 \\
\hline \multirow[t]{3}{*}{$\mathrm{DMT}$} & $a(*)$ & 48.84 & 2.8107 & 44.19 & 55.60 & 127.11 & 10.000 & 110.31 & 134.15 \\
\hline & $b(\mathrm{~ns})$ & -6.38 & 0.6899 & -7.868 & -5.280 & -7.38 & 0.7798 & -8.5001 & -5.9552 \\
\hline & $c(*)$ & 0.0951 & 0.0119 & 0.0752 & 0.1203 & 0.0813 & 0.0102 & 0.0720 & 0.0920 \\
\hline
\end{tabular}

Note. ${ }^{*} \mathrm{DML}=$ dry matter leaf; DMS $=$ dry matter stem; DMR $=$ dry matter root; DMSH $=$ dry matter shoot and $\mathrm{DMT}=$ total dry matter.

Therefore, it is concluded that for the Logistic model, the parameter estimates $a, b$ and $c$ of periods differ at $5 \%$ probability. This, as for the traits of mass of fresch matter, also, it is concluded that the sowing periods have influence on the mass production of dry matter.

Thes setting quality criteria of the Gompertz and Logistic models are very important to compare which is the best model. It is observed that for the traits of FML, FMS, FMR, FMSH and FMT for the first period, the values for criteria R, AIC, DPR, DMA and MAPE were similar for both models, indicating that in order overall, there was a good adjustment of the models. For the EPM evaluation criteria, the values differed between the adjusted models and between the sowing periods for both the fresch matter mass and the dry matter mass of the traits (Table 4). 
However, for second period, the quality of fit of the models was lower in relation to the characteristics of first period. It can be inferred that in second period, when sowing of the sunn hemp was later, flowering occurred at 88 DAS, that is, it had a lower cycle when compared to first period, when flowering occurred at 100 DAS, and this may have contributed to the quality of fit of the models. Similar results were observed for the traits DML, DMS, DMR, DMSH and DMT (Table 4).

Table 4. Criteria for evaluation the quality fit: coefficient of determination $\left(R^{2}\right)$, Akaike information criterion (AIC), standard deviation of residuals (SDR), mean absolute deviation (MAD), mean absolute percentage error (MAPE), and mean prediction error (MPE) for Gompertz and Logistic models, for traits productive of mass of fresch matter, using days after sowing during two sowing periods

\begin{tabular}{|c|c|c|c|c|c|c|c|c|c|c|c|c|}
\hline \multirow{2}{*}{ Traits } & \multicolumn{6}{|c|}{ First sowing period (October 22, 2014) } & \multicolumn{6}{|c|}{ Second sowing period (December 03, 2014) } \\
\hline & $\overline{R^{2}}$ & AIC & DPR & DMA & MAPE & EPM & $\overline{R^{2}}$ & AIC & DPR & DMA & MAPE & EPM \\
\hline \multicolumn{13}{|c|}{ Model of Gompertz } \\
\hline FML & 0.61 & 5.48 & 29.31 & 0.0006 & 0.0024 & -0.2354 & 0.49 & 4.98 & 20.92 & 0.0008 & 0.0057 & -0.5038 \\
\hline FMS & 0.67 & 6.77 & 55.74 & 0.0034 & 0.0075 & -0.7465 & 0.59 & 6.57 & 48.12 & 0.0005 & 0.0016 & 0.1403 \\
\hline FMR & 0.63 & 4.17 & 15.16 & 0.0000 & 0.0004 & 0.0358 & 0.41 & 3.36 & 9.70 & 0.0000 & 0.0052 & -0.4552 \\
\hline FMSH & 0.67 & 7.54 & 81.78 & 0.0047 & 0.0069 & -0.6901 & 0.57 & 7.28 & 68.78 & 0.0019 & 0.0041 & -0.3645 \\
\hline FMT & 0.69 & 7.83 & 95.59 & 0.0049 & 0.0062 & -0.6226 & 0.56 & 7.51 & 77.25 & 0.0016 & 0.0031 & -0.2704 \\
\hline DML & 0.62 & 2.28 & 5.92 & 0.0001 & 0.0018 & -0.1792 & 0.45 & 2.42 & 6.06 & 0.0000 & 0.0011 & 0.0925 \\
\hline DMS & 0.69 & 3.91 & 13.37 & 0.0002 & 0.0000 & 0.2025 & 0.54 & 4.58 & 17.88 & 0.0087 & 0.1030 & 9.0606 \\
\hline DMR & 0.60 & 1.93 & 4.95 & 0.0002 & 0.0065 & 0.6539 & 0.42 & 0.98 & 2.95 & 0.0001 & 0.0045 & 0.3674 \\
\hline DMSH & 0.69 & 4.57 & 18.54 & 0.0001 & 0.0005 & 0.0504 & 0.53 & 5.13 & 23.46 & 0.0082 & 0.0696 & 6.1264 \\
\hline DMT & 0.67 & 4.96 & 22.56 & 0.0003 & 0.0015 & 0.1468 & 0.53 & 5.32 & 25.88 & 0.0082 & 0.0628 & 5.5258 \\
\hline \multicolumn{13}{|c|}{ Model Logistic } \\
\hline FML & 0.60 & 5.50 & 29.61 & 0.0041 & 0.0174 & -1.7385 & 0.49 & 4.99 & 21.86 & 0.0029 & 0.0198 & -1.7393 \\
\hline FMS & 0.67 & 6.78 & 56.20 & 0.0102 & 0.0228 & -2.2753 & 0.60 & 6.56 & 48.10 & 0.0083 & 0.0256 & -2.2600 \\
\hline FMR & 0.63 & 4.17 & 15.18 & 0.0014 & 0.0128 & -1.2782 & 0.41 & 3.36 & 9.69 & 0.0008 & 0.0153 & -1.3448 \\
\hline FMSH & 0.66 & 7.56 & 82.64 & 0.0158 & 0.0230 & -2.3043 & 0.57 & 7.28 & 69.00 & 0.0122 & 0.0260 & -2.2898 \\
\hline FMT & 0.67 & 7.84 & 95.50 & 0.0175 & 0.0220 & -2.2002 & 0.56 & 7.52 & 77.46 & 0.0122 & 0.0236 & -2.0738 \\
\hline DML & 0.62 & 2.29 & 5.95 & 0.0009 & 0.0169 & -1.6904 & 0.46 & 2.42 & 6.04 & 0.0004 & 0.0131 & -0.0131 \\
\hline DMS & 0.69 & 3.91 & 13.37 & 0.0011 & 0.0114 & -1.1383 & 0.57 & 4.52 & 17.32 & 0.0075 & 0.0884 & 7.7768 \\
\hline DMR & 0.60 & 1.92 & 4.94 & 0.0002 & 0.0051 & -0.5108 & 0.42 & 0.98 & 2.94 & 0.0001 & 0.0079 & -0.6915 \\
\hline DMSH & 0.69 & 4.57 & 18.56 & 0.0018 & 0.0127 & -1.2680 & 0.55 & 5.08 & 22.87 & 0.0054 & 0.0459 & 4.0380 \\
\hline DMT & 0.68 & 4.96 & 22.57 & 0.0020 & 0.0115 & -1.1456 & 0.55 & 5.28 & 25.29 & 0.0092 & 0.0698 & 6.1386 \\
\hline
\end{tabular}

Note. ${ }^{*} \mathrm{FML}=$ fresh matter leaf; FMS $=$ fresh matter stem; FMR $=$ fresh matter root; FMSH $=$ fresh matter shoot and FMT = total fresh matter; DML = dry matter leaf; DMS = dry matter stem; DMR = dry matter root; DMSH $=$ dry matter shoot and DMT $=$ total dry matter.

According to Moura, Souza, Silva, Soares, Carmo, and Brandão (2011), a study on the growth Expolinear models, Logistic and Gompertz on the dry matter accumulation of cultures feijão-cowpea and maize found values of the coefficient of determination higher than 0.97 for all models using as a variable independent DAS; Prado et al. (2013) studied the growth of fruit dwarf coconut, compared Logistic and Gompertz model, according to the following set of criteria: the adjusted coefficient of determination $\left(R^{2} a j\right)$, the residual standard deviation (RSD) and Akaike information criterion (AIC), Reis, Cecon, Puiatti, and Finger (2014) comparing five non-linear regression models to describe the accumulation of different dry mass of garlic over time and Lúcio, Sari, Rodrigues, Bevilaqua, Voss, Copetti, and Faé (2016), a study on nonlinear models for estimating cherry tomato yield. Thus, these works are in line with the research objective, adjusting the Gompertz and Logistic models for the productive traits of sunn hemp.

In Figures 1, 2, 3 and 4 are presented mented the growth curves and the corresponding equation and is the inflection point (IP) the models of Gompertz and Logistic in the two sowing periods. 

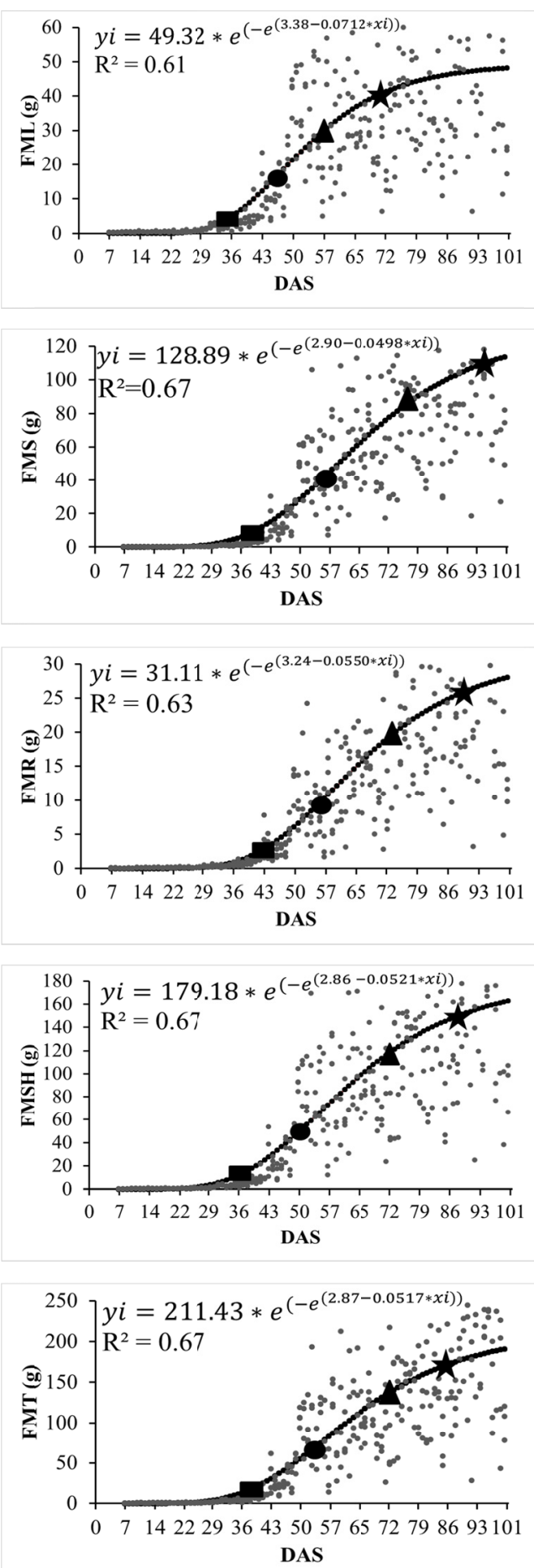
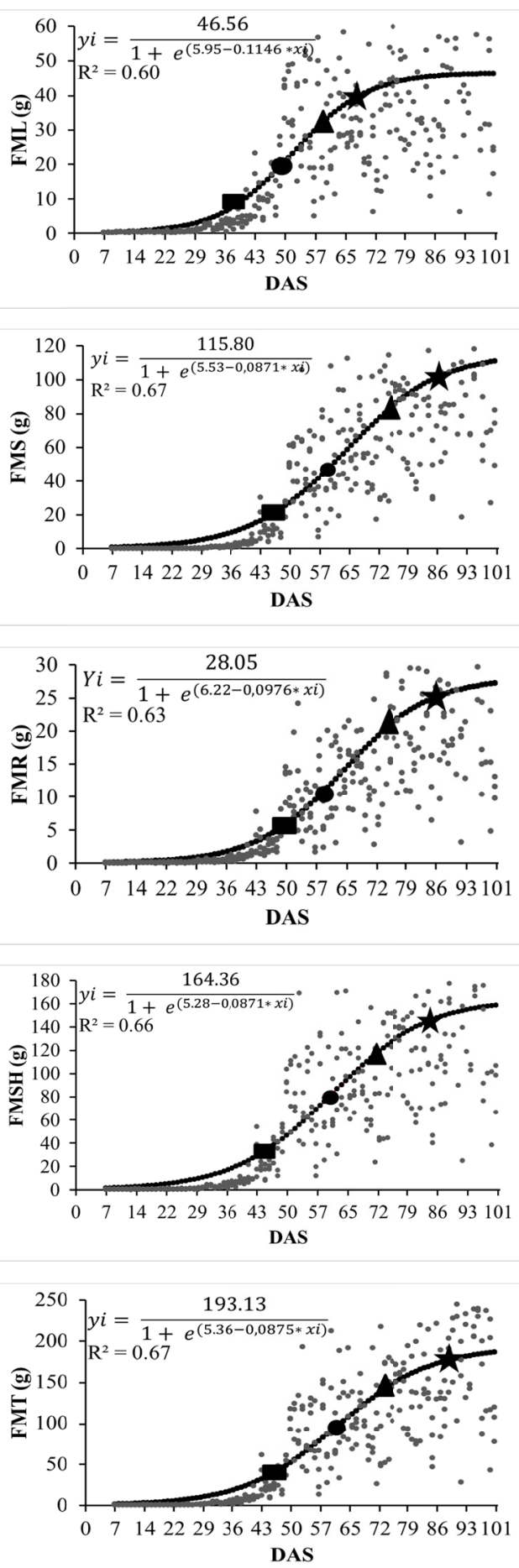

Figure 1. Adjusted to fit Gompertz and Logistic, and IP (inflection point), for the productive traits, fresh matter leaf (FML); fresh matter stem (FMS); fresh matter root (FMR); fresh matter shoot (FMSH) and total fresh matter (FMT), of sunn hemp in first sowing period (October 22, 2014)

Note. ${ }^{*}$ First sowing periods $=$ October 22, 2014 and evaluation $=$ October 29, $2014(x i=7) .{ }^{* *}$ Left column Gompertz model and rigth column Logistic model. - maximum acceleration points (map); • Inflection points; $\Delta$ maximum deceleration points (mdp) and $\star$ asymptotic deceleration points (adp) (xi; yi). 

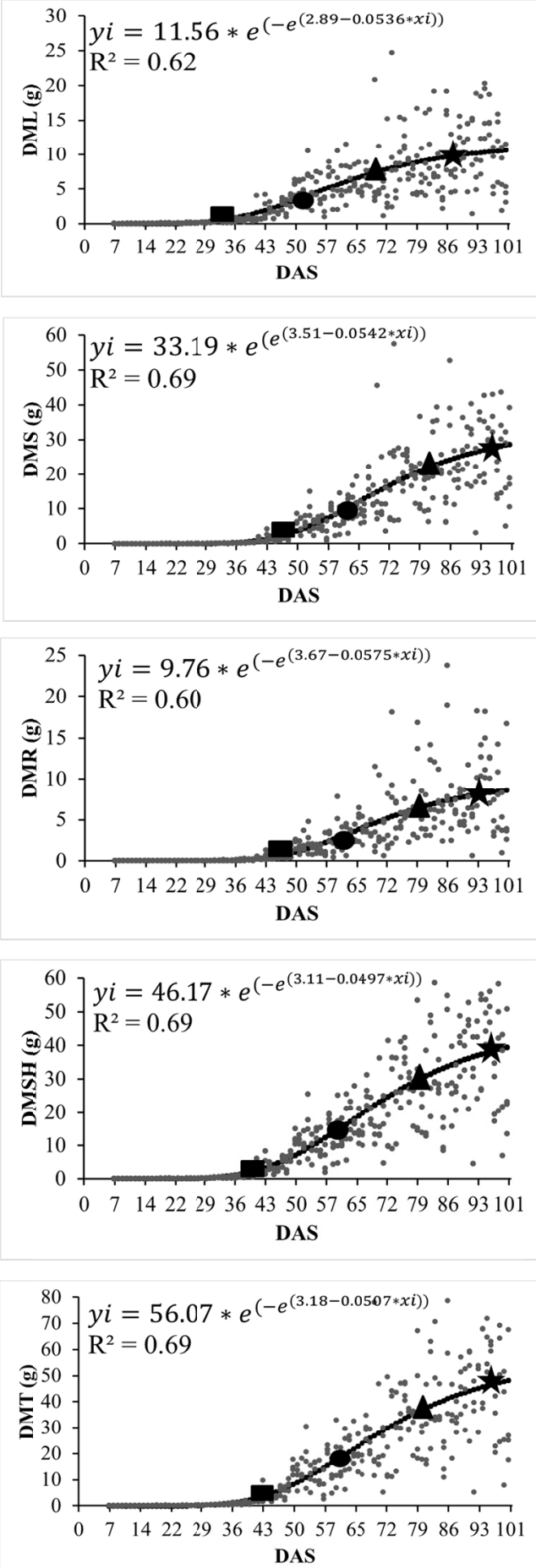
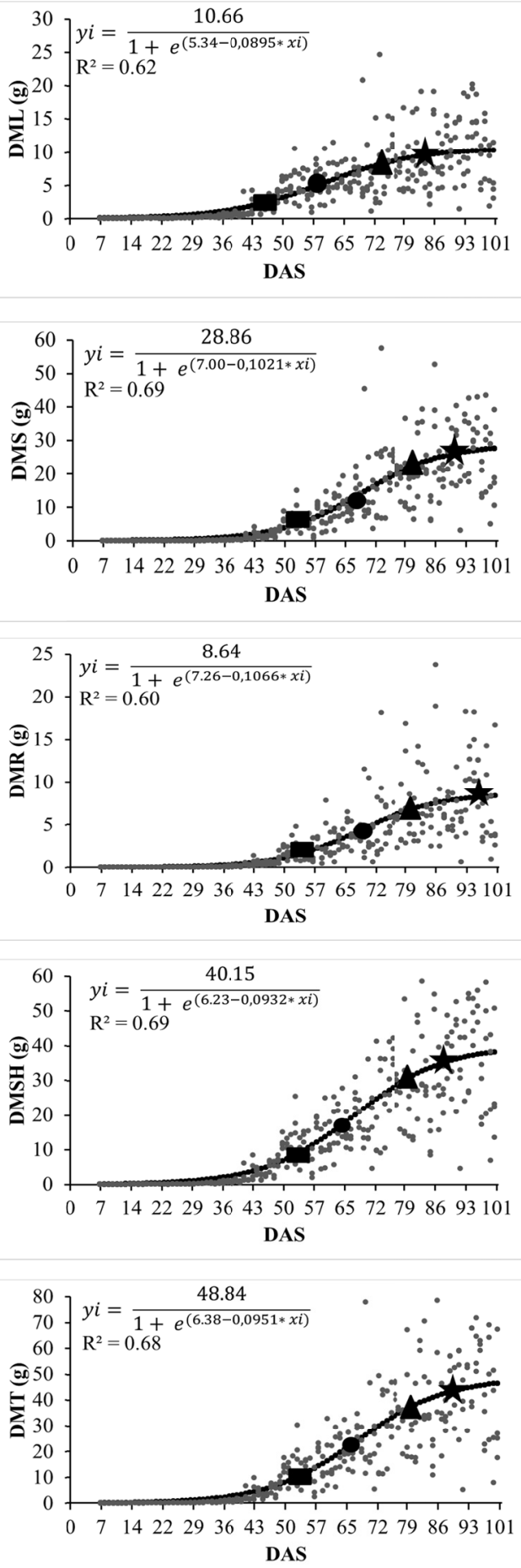

Figure 2. Adjusted to fit Gompertz and Logistic, and IP (inflection point), for the productive traits dry matter leaf (DML); dry matter stem (DMS); dry matter root (DMR); dry matter shoot (DMSH) and total dry matter (DMT), of sunn hemp in first sowing period (October 22, 2014)

Note. ${ }^{*}$ First sowing periods $=$ October 22, 2014 and evaluation $=$ October 29, $2014(x i=7) .{ }^{* *}$ Left column Gompertz model and rigth column Logistic model. - maximum acceleration points (map); • Inflection points; $\Delta$ maximum deceleration points (mdp) and $\star$ asymptotic deceleration points (adp) (xi; yi). 

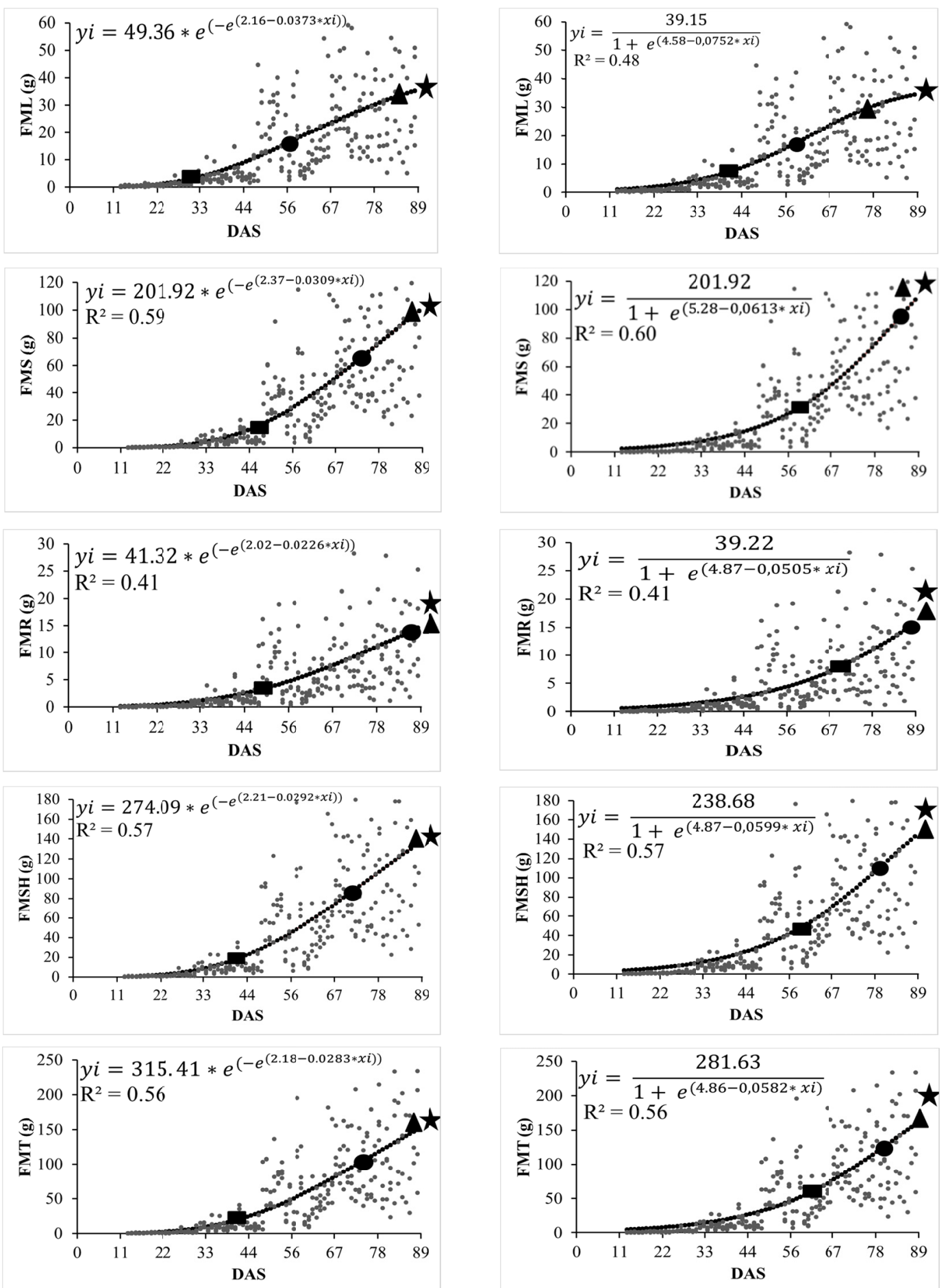

Figure 3. Adjusted to fit Gompertz and Logistic, and IP (inflection point), for the productive traits, fresh matter leaf (FML); fresh matter stem (FMS); fresh matter root (FMR); fresh matter shoot (FMSH) and total fresh matter (FMT), of sunn hemp in second sowing period (December 3, 2014)

Note. ${ }^{*}$ Second sowing periods $=$ December 3, 2014 and evaluation $=$ December 16, $2014(x i=13) .{ }^{* *}$ Left column Gompertz model and rigth column Logistic model. - maximum acceleration points (map); • Inflection points; $\Delta$ maximum deceleration points (mdp) and $\star$ asymptotic deceleration points (adp) (xi; yi). 

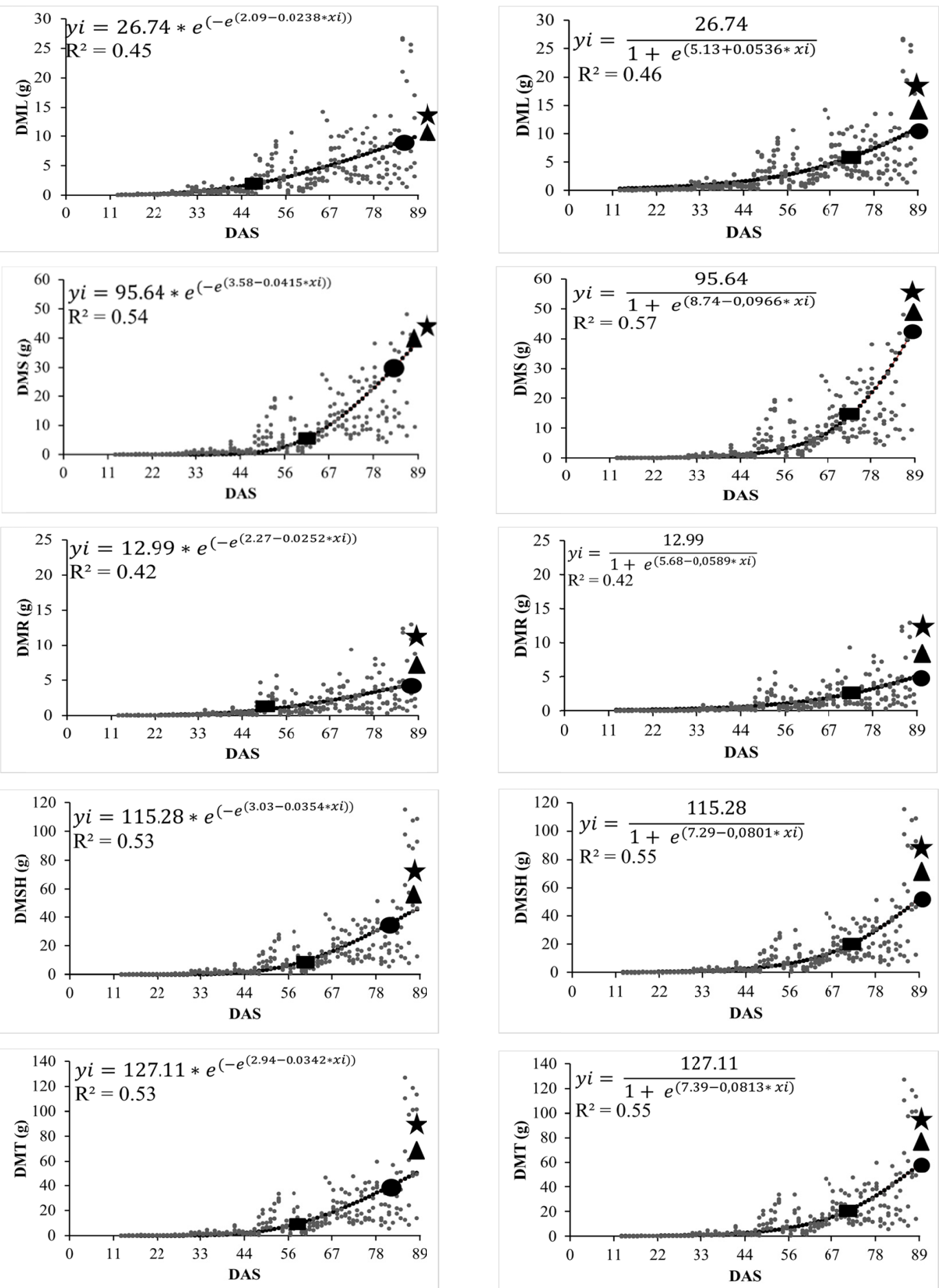

Figure 4. Adjusted to fit Gompertz and Logistic, and IP (inflection point), for the productive traits dry matter leaf (DML); dry matter stem (DMS); dry matter root (DMR); dry matter shoot (DMSH) and total dry matter (DMT), of sunn hemp in second sowing period (December 3, 2014)

Note. ${ }^{*}$ Second sowing periods $=$ December 3, 2014 and evaluation $=$ December 16, $2014(x i=13) .{ }^{* *}$ Left column Gompertz model and rigth column Logistic model. - maximum acceleration points (map); • Inflection points; $\Delta$ maximum deceleration points (mdp) and $\star$ asymptotic deceleration points (adp) (xi; yi).

It is observed that the maximum acceleration point (map) occurs at the beginning of the curve and ends when the culture reaches the IP, at this moment it is possible to infer about the maneuvers to be carried out in the jungle grove such as fertilization, pest and diseases, herbicide application, because the plant will respond to these 
managements efficiently. Then, the curve starts to stabilize the growth, at which point the maximum deceleration point (mdp) occurs, stabilizing the growth until reaching the point of asymptotic deceleration (adp), at this stage the crop reaches flowering. Therefore, all these points are important for future projections and for planning activities with culture.

\section{Conclusions}

The Gompertz and Logistic models compared between sowing periods through the parameters of the confidence intervals for the traits fresch matter mass and dry matter mass leaf, stem, root, shoot and total differ.

The Gompertz and Logistic models, adjusted to fresch matter mass and dry matter mass data showed good ft.

\section{Acknowledgements}

To the National Council of Scientific and Technological Development (CNPQ), the Coordination of Improvement of Personnel of Superior Level (CAPES) and the Foundation of Amparo the Research of the state of Rio Grande do Sul (FAPERGS), by the granting of scholarship to the authors. Student fellows and volunteers assisted in data collection.

\section{References}

Bem, C. M., Cargnelutti Filho, A., Facco, G., Schabarum, D. E., Silveira, D. L., Simões, F. M., \& Uliana, D. B. (2017). Growth models for morphological traits of sunn hemp. Semina: Ciências Agrárias, 38, $2933-2944$. https://doi.org/10.5433/1679-0359.2017

Fernandes, T. J., Pereira, A. A., Muniz, J. A., \& Savian, T. V. (2014). Seleção de modelos não lineares para a descrição de curvas de crescimento do fruto do cafeeiro. Coffee Science, 9, 207-215.

Gomes, A. C. dos S., Robaina, A. D., Peiter, M. X., Soares, F. C., \& Parizi, A. R. C. (2014). Modelo para estimativa da produtividade para a cultura da soja. Ciência Rural, 44, 43-49. https://doi.org/10.1590/ S0103-84782013005000145

Lúcio, A. D., Sari, B. G., Rodrigues, M., Bevilaqua, L. M., Voss, H. M. G., Copetti, D., \& Faé, M. (2016). Modelos não-lineares para a estimativa da produção de tomate do tipo cereja. Ciência Rural, 46, $233-241$. https://dx.doi.org/10.1590/0103-8478

Maia, E., Siqueira, D. L. de, Silva, F. F., Peternelli, L. A., \& Salomão, L. C. C. (2009). Método de comparação de modelos de regressão não-lineares em bananeiras. Ciência Rural, 39, 1380-1386. https://doi.org/10.1590/ S0103-84782009000500012

Mangueira, R. A. F., Savian, T. V., Muniz, J. Á., Sermarini, R. A., \& Crosariol Neto, J. (2016). O modelo Logístico considerando diferentes distribuições para os erros aplicado a dados de altura de milho. Revista Brasileira de Biometria, 34, 317-333.

Mischan, M. M., \& Pinho, S. Z. (2014). Modelos não lineares: Funções assintóticas de crescimento (1st ed.). São Paulo: Cultura Acadêmica.

Moura, M. S. B., Souza, L. S. B., Silva, T. G. F., Soares, J. M., Carmo, J. F. A., \& Brandão, E. O. (2011). Modelos de crescimento para o feijão-caupi e o milho, sob sistemas de plantios exclusivo e consorciado, no Semiárido brasileiro. Revista Brasileira de Agrometeorologia, 16, 275-284. https://doi.org/10.1590/S141543662013001000009

Muniz, J. A., Nascimento, M. S., \& Fernandes, T. J. (2017). Nonlinear models for description of cacao fruit growth with assumption violations. Revista Caatinga, 30, 250-257. https://doi.org/10.1590/1983-21252017

Prado, T. K. L., Savian, T. V., \& Muniz, J. A. (2013). Ajuste dos modelos Gompertz e logístico aos dados de crescimento de frutos de coqueiro anão verde. Ciência Rural, 43, 803-809. https://doi.org/10.1590/ S0103-84782013005000044

R Development Core Team. (2017). R: A language and environment for statistical computing. Vienna: R Foundation for Statistical Computing.

Reis, R. M., Cecon, P. R., Puiatti, M., Finger, F. L., Nascimento, M., Silva, F. F., .. Silva, A. R. (2014). Modelos de regressão não linear aplicados a grupos de acessos de alho. Horticultura Brasileira, 32, 178-183. https://doi.org/10.1590/S0102-05362014000200010

Sousa, G. M. M. de. (2011). Adubação orgânica e densidade de plantas em crotaláriajuncea antecedendo o arroz (Dissertação, Mestrado em Ciência do Solo, Universidade Federal Rural do Semi-Árido). 
Streck, N., Bosco, L. C., Lucas, D. D. P., \& Lago, I. (2008). Modelagem da emissão de folhas em arroz. Pesquisa Agropecuária Brasileira, 43, 559-567. https://doi.org/10.1590/S0100-204X2008000500002

Wutke, E. B., Calegari, A., \& Wildner, L. do P. (2014). Espécies de adubos verdes e plantas de cobertura e recomendações para seu uso. In O. F. de Lima Filho, E. J. Ambrosano, F. Rossi, \& J. A. D. Carlos (Eds.), Adubação verde e plantas de cobertura no Brasil: Fundamentos e prática (pp. 59-168). Brasília: Embrapa.

\section{Copyrights}

Copyright for this article is retained by the author(s), with first publication rights granted to the journal.

This is an open-access article distributed under the terms and conditions of the Creative Commons Attribution license (http://creativecommons.org/licenses/by/4.0/). 